\title{
Molecular and Morphometric Identification of P. Thornei and P. Neglectus in Southwest of Iran
}

\author{
Fatemeh Fayazi ${ }^{1 *}$, Reza Farokhi-Nejd ${ }^{1}$, Ali Reza Ahmadi ${ }^{2}$, Hamid Rajabi Memari ${ }^{3}$ and Zeynab Bahmani ${ }^{1}$ \\ ${ }^{1}$ Department of Plant Protection, College of Agriculture, Shahid Chamran University, Ahvaz, Iran \\ ${ }^{2}$ Department of Plant Protection, Agriculture and Natural Resources Research Centre of Khuzestan, Ahvaz, Iran \\ ${ }^{3}$ Department of Agronomy and Plant Breeding, College of Agriculture, Shahid Chamran University, Ahvaz, Iran
}

\begin{abstract}
Root lesion nematodes are considered as important agents of wheat yield reduction in most parts of the wheat growing areas. To elucidate disease situation in Khuzestan, a southwestern province of Iran, 40 soil \& wheat root samples were collected. Morphological studies indicated that disease casual agents belong to Pratylenchus thornei and $P$. neglectus species. Morphometric studies showed that Differences exist in the body length compared with the studies done so far on these two species of nematode. The DNA of the two species, namely Pratylenchus thornei and $P$. neglectus, were extracted concidering Madani et al. [1], Silva et al. [2] and Waeyenberg et al. [3] plus some modifications. The quantity and quality of extracted DNA and its ability in DNA amplification and clearance of PCR bands were compared and the results showed that modified methods of Madani et al. [1] and Waeyenberg et al. [3] were the best methods for $P$. thornei and $P$. neglectus species. Polymerase chain reaction (PCR) and speciesspecific primers were used to identify $P$. thornei and $P$. neglectus.
\end{abstract}

Keywords: DNA; PCR; P. neglectus; P. thorn

\section{Introduction}

Wheat (Triticum aestivum L.) is an important grain in Iran. Iran has been ranked as the 12th producer of wheat, for producing more than 13.5 Mt during 2008-2009 [4]. Khuzestan, which is located in the southwest of Iran, is the second most important cereal producing province in the country due to the total production of $1.2 \mathrm{Mt}$ during 2008-2009 [5].

Pratylenchus nematodes are common endoparasite of plant all around the world. The mentioned genus cause necrotic lesions due to being migratory and obligating parasites that invade the cortex of roots, tubers, and bulbs of plant. This reduces the yields [6,7]. Several cereal and legume crops are damaged by the cereal and legume rootlesion nematodes, namely $P$. thornei and $P$. neglectus, in many parts of the world such as the Mediterranean region, America, the Indian Subcontinent and Australia [8,9]. The two species $P$. thornei and $P$. neglectus are the most common species of Pratylenchus in Iran [10]. Ahmadi et al. [11] showed that the population density of P. thornei in wheat root samples ranged from 1-351 nematodes/g of root sample in Khuzestan.

Loof (1991) reported currently that the genus Prtylenchus that includes more than 60 species could be differentiated only by means of minor morphological and morphometric differences of adult females and males. Several characters can be used in the distinction of various species of this genus from each other. They are as follow: the number of annuli in the lip region, the presence or the absence of a spermatheca in females, the presence or the absence of males, the number of lines in the lateral field, and the shape of the tail $[12,13]$. Intraspecific morphological variability within the genus Pratylenchus is well documented for the most of the characters used in species identification; hence, causes difficulties in identifying species [13]. The use of molecular diagnostic tools is a practical solution to overcome such a problem. PCR-based methods are relatively rapid and very reliable; the possess high discriminating potentials, do not rely on the expressed products of the genome, and are independent of the environmental influence and the stage of the nematode life cycle. A PCR-based assay was used for the identification of six species of Pratylenchus through forward and reverse species-specific primers that were designed from the internal variable portion of the D3 expansion region of the $26 \mathrm{~S} \mathrm{rDNA}$ [14]. AlBanna et al. [14] distinguished P. neglectus and P. thornei along with four other Pratylenchus spp. using PCR and species-specific primers derived from the internal variable portion of the $\mathrm{D} 3$ expansion region of the $28 \mathrm{~S}$ rDNA. The detection and identification of $P$. thornei and $P$. neglectus from soil developed and two species were differentiated by PCR products of $144 \mathrm{bp}$ for $P$. neglectus and $288 \mathrm{bp}$ for $P$. thornei [15].

In the present study, using nucleotide sequences of the $\mathrm{D} 3$ expansion region of $28 \mathrm{~S}$ rRNA, molecular methods were investigated for the aim of identifying P. thornei and P. neglectus.

\section{Materials and Methods}

Forty soil and wheat root samples were collected from Masjed Solleiman, Behbahan, Bagh Mallek and Shoushtar to elucidate disease situation in Khuzestan. Nematodes were extracted from soil samples using the Jenkins [16] method. We examined the standard morphological and morphometric characters of root-lesion nematodes [13]. Adult females were morphologically identified as either $P$. thornei or $P$. neglectus. Root-lesion nematodes were reared on carrot discs $[17,18]$. Then nematodes were extracted from carrot discs through Whitehead and Hemming methods [19].

Specimens used in this study were extracted from infested roots 24 to $48 \mathrm{hrs}$ after the incubation [20]. They were then handpicked,

*Corresponding author: Fatemeh Fayazi, Department of Plant Protection, College of Agriculture, Shahid Chamran University, Ahvaz, Iran, Tel: +98-09177758271; Fax: +98-0772-4243385; E-mail: fayazi.fatemeh@yahoo.com

Received April 27, 2012; Accepted June 29, 2012; Published July 03, 2012

Citation: Fayazi F, Farokhi-Nejd R, Ahmadi AR, Memari HR, Bahmani Z (2012) Molecular and Morphometric Identification of $P$. Thornei and $P$. Neglectus in Southwest of Iran. J Plant Pathol Microb 3:123. doi:10.4172/2157-7471.1000123

Copyright: @ 2012 Fayazi F, et al. This is an open-access article distributed under the terms of the Creative Commons Attribution License, which permits unrestricted use, distribution, and reproduction in any medium, provided the original author and source are credited. 
Citation: Fayazi F, Farokhi-Nejd R, Ahmadi AR, Memari HR, Bahmani Z (2012) Molecular and Morphometric Identification of $P$. Thornei and $P$. Neglectus in Southwest of Iran. J Plant Pathol Microb 3:123. doi:10.4172/2157-7471.1000123

Page 2 of 5

\begin{tabular}{|c|c|c|c|c|c|}
\hline \multirow[t]{2}{*}{ characters } & \multicolumn{4}{|c|}{ counties } & \multirow{2}{*}{$\begin{array}{c}\text { Total } \\
\text { Mean } \pm S D\end{array}$} \\
\hline & Masjed Solleiman & Behbahan & Bagh Mallek & Shoushtar & \\
\hline $\mathbf{n}$ & 10 & 10 & 10 & 10 & 40 \\
\hline $\mathbf{L}$ & $715-552(547.2 \pm 6.4)$ & $595-690(576.2 \pm 6.4)$ & $425-620(616 \pm 6.4)$ & $512-730(616 \pm 6.4)$ & $606 \pm 27.6(425-730)$ \\
\hline a & $33.9-40(30.9 \pm 6.3)$ & $27.6-35.6(25.7 \pm 6.4)$ & $30-39.8(35 \pm 5.6)$ & $27.5-40.2(31 \pm 5.4)$ & $33.9 \pm 5.4(27.5-35.6)$ \\
\hline b & $5.8-6.9(5 \pm 0.9)$ & $6.2-6.9(6.4 \pm 0.7)$ & $4.1-7.3(6.1 \pm 0.6)$ & $5.4-6.7(5.7 \pm 0.8)$ & $6.3 \pm 0.7(4.1-7.3)$ \\
\hline $\mathbf{b}^{\prime}$ & $3.8-6.2(5 \pm 0.9)$ & $4-5.5(4.6 \pm 0.7)$ & $3.4-5.5(4.8 \pm 1.1)$ & $5.2-5.5(4.1 \pm 1.1)$ & $4.6 \pm 1(3.4-6.2)$ \\
\hline c & $18.9-22.1(20.1 \pm 2.9)$ & $12.8-22.3(20 \pm 2)$ & $19.9-23.8(20 \pm 1.5)$ & $18-20.9(21 \pm 2.5)$ & $20.5 \pm 2.1(12.8-23.8)$ \\
\hline$c^{\prime}$ & $1.3-2.6(1.9 \pm 0.5)$ & $1.7-2.5(1.9 \pm 0.5)$ & $1.6-2.1(2 \pm 0.4)$ & $1.5-2.6(2.2 \pm 0.4)$ & $2.1 \pm 0.4(1.3-2.6)$ \\
\hline $\mathbf{V}$ & $77-79(77.6 \pm 1.4)$ & $76-78(77 \pm 1.2)$ & $79-79.9(77.3 \pm 1.05)$ & $76-78(78 \pm 1.3)$ & $77.6 \pm 1.2(76-79.9)$ \\
\hline Stylet & $15-16(15.3 \pm 0.5)$ & $15-16(16 \pm 1.1)$ & $16-18(16.3 \pm 0.7)$ & $15-17(15.9 \pm 1)$ & $16.1 \pm 1(15-18)$ \\
\hline m & $44.4-44.6(44 \pm 2.4)$ & $45-50.3(45.5 \pm 2.6)$ & $41-48(44.4 \pm 3)$ & $45.2-48.9(47 \pm 2.6)$ & $46 \pm 2.6(41-50.3)$ \\
\hline Oeso $^{1}$ & $99-103(100 \pm 2.1)$ & $97-99(98.3 \pm 4.4)$ & $83-96(95 \pm 6.4)$ & $93-110(103.5 \pm 8.4)$ & $99.6 \pm 6.5(83-110)$ \\
\hline Over $^{2}$ & $30-45(36 \pm 7.7)$ & $30-39(38 \pm 2.1)$ & $35-49(47 \pm 8.4)$ & $25-55(41.8 \pm 11.54)$ & $41.7 \pm 8.9(25-55)$ \\
\hline Exc.pore & $65-90(86.5 \pm 8.7)$ & $87-95(88.2 \pm 1.5)$ & $78-90(75.8 \pm 1.1)$ & $90(90 \pm 0)$ & $85.1 \pm 9.3(65-95)$ \\
\hline Bw & $17-20(18 \pm 1.5)$ & $19-26(19.4 \pm 1)$ & $17-21(8 \pm 1.9)$ & $15-19(17 \pm 1.7)$ & $18.9 \pm 1.9(15-26)$ \\
\hline G\% & $23(22.4 \pm 2.9)$ & $25.3(24.4 \pm 1.2)$ & $18.9-19(19 \pm 5.4)$ & $21-24.2(22.12 \pm 2.7)$ & $22.1 \pm 4.6(18.9-24.2)$ \\
\hline Pus & $15-18(16 \pm 4.7)$ & $20-27(19.4 \pm 2)$ & $14-20(19.4 \pm 2.9)$ & $19-27(18.7 \pm 4.9)$ & $19.6 \pm 4.3(14-27)$ \\
\hline Tail & $25-45(34.2 \pm 7.2)$ & $35-40(35 \pm 10.5)$ & $30(30 \pm 0)$ & $26-30(30.6 \pm 4.7)$ & $34.4 \pm 6.8(25-45)$ \\
\hline ABW & $11(11 \pm 0)$ & $11-13(12.7 \pm 2.2)$ & $11-13(13 \pm 0.5)$ & $11-14(11.9 \pm 1.5)$ & $14.8 \pm 1.3(11-14)$ \\
\hline DGO & 2 & 2 & 2 & 2 & $2 \pm 0(2)$ \\
\hline $\mathrm{mB} \%$ & $52.4-53.6(53 \pm 0.4)$ & $51-62.4(59 \pm 5.1)$ & $51(51 \pm 0)$ & $51.9-57(55.3 \pm 3)$ & $55.3 \pm 4.3(51-62.4)$ \\
\hline GI & $90-125(107 \pm 12.1)$ & $95-99.1(99 \pm 6.3)$ & $125(125 \pm 0)$ & $95-110(109 \pm 14.5)$ & $107.6 \pm 12.8(90-125)$ \\
\hline V-an & $79-125(108 \pm 17)$ & $90-120(100 \pm 12.9)$ & $78-110(199.3 \pm 14.8)$ & $98-119(116.9 \pm 6.8)$ & $104.1 \pm 15.6(78-125)$ \\
\hline
\end{tabular}

1: Length of esophagus

2: The esophageal glands overlap the intestine

Table 1: Morphometric data of females of Pratylenchus thornei from 4 counties were examined. Measurements are in $\mu \mathrm{m}$ and expressed as means \pm standard deviation (range).

killed and fixed with a solution of $10 \%$ formaline $+1 \%$ acetic acid $+1 \%$ glycerine $+88 \%$ distilled water, heated to $80^{\circ} \mathrm{C}$, then processed to pure glycerine for microscope observations according to De Grisse [21]. Measurements were done with the aid of a camera Lucida and an ocular micrometer. Abbreviations used are defined by Loof [13].

In this study, three different modified DNA extraction methods were used. The first method was a modificated protocol adapted from Madani et al. [1]. Ten microliter $\mathrm{dH}_{2} \mathrm{O}, 3 \mu$ Proteinase $\mathrm{K}(0.6 \mathrm{mg} / \mathrm{ml})$ and $3 \mu \mathrm{l} 1 \mathrm{X} \mathrm{Mg}$-free thermophilic DNA polymerase reaction buffer were added to each sterile $1.5 \mathrm{ml}$ microtube containing ten adult nematodes. Then $\mathrm{dH}_{2} \mathrm{O}$ was added to the sample to the final volume of $41 \mu \mathrm{l}$ and then sample was incubated at $65^{\circ} \mathrm{C}$ for $1 \mathrm{hr}$. After the first incubation accomplished, the sample was incubated further at $95^{\circ} \mathrm{C}$ for 15 minutes before storing it at $-20^{\circ} \mathrm{C}$. In the second method, DNA was extracted from nematodes regarding the protocol described by Waeyenberg et al. [3] with some modification. Ten adult nematodes were put into $20 \mu \mathrm{l}$ of sterilized water on a concave glass slide. Then $10 \mu$ of suspended nematode pieces were pipetted into a $0.2 \mathrm{ml}$ sterile microtube containing $8 \mu \mathrm{l}$ of lyses buffer $\left(500 \mathrm{mM} \mathrm{KCl} ; 100 \mathrm{mM}\right.$ Tris-Cl, $\mathrm{pH} 8.3 ; 15 \mathrm{mM} \mathrm{MgCl}_{2}$ ; $10 \mathrm{mM}$ dithiothreitol [DTT]; $4.5 \%$ Tween 20 ; and $0.1 \%$ gelatin). The tube content was frozen at $-20^{\circ} \mathrm{C}$ for at least $20 \mathrm{~min}$, thawed, and then $2 \mu \mathrm{l}$ of proteinase $\mathrm{K}(600 \mu \mathrm{g} / \mathrm{ml})$ were added. The tubes were incubated at $65^{\circ} \mathrm{C}$ in a water bath for $1 \mathrm{~h}$, and consecutively at $95^{\circ} \mathrm{C}$ for $10 \mathrm{mins}$ to inactive proteinase $\mathrm{K}$. The nematode lyses mix was centrifuged at $16,000 \times \mathrm{g}$ for $5 \mathrm{~min}$ and the supernatant was transferred to a new 0.2 $\mathrm{ml}$ tube and stored in $-20^{\circ} \mathrm{C}$ until it used as the DNA template.

In the third method, modifying Silva et al. [2] method, DNA was extracted from nematodes. Ten sterilized adult nematodes with $10 \mu \mathrm{l}$ of sterilized water were put into $0.2 \mathrm{ml}$ microtube with $20 \mu \mathrm{l}$ of lyses buffer (100mM Tris-Cl, pH 8.3; $1.4 \mathrm{mM} \mathrm{NaCl} ; 20 \mathrm{mM}$ EDTA; and $0.1 \%$ B-Mercaptioethanol). Afterwards, samples were frozen for $20 \mathrm{mins}$ and then were immediately placed at $65^{\circ} \mathrm{C}$ for $1 \mathrm{~h}$. The volumes of 30 $\mu \mathrm{l}, 24 \mu \mathrm{l}$ and $6 \mu \mathrm{l}$ phenol, chloroform and isoamilalcohol were added to samples respectively. After applying severe shock and complete mixture, the samples centrifuged for 15 mins at $13000 \mathrm{rpm}$ and the supernatant phase was transferred to the new microtube. Then, $30 \mu \mathrm{l}$ of cold isopropanol were added and frozen for $10 \mathrm{~min}$.

The species-specific forward primer PTHO and the common reverse primer D3B [14] were used to identify $P$. thornei. The species-specific forward primer PNEG-F and the common reverse primer D3B5 were used to identify $P$. neglectus [15]. The species-specific forward primers PTHO and PNEG-F1 were designed based on the variable region in the alignment of the 28S rRNA D3 expansion domains. The species-specific backward primers D3B5 and D3B were selected from the conserved region of the same D3 expansion domain in order to produce a PCR fragment with different sizes [15].

Four isolates of $P$. thornei and $P$. neglectus from Masjed Solleiman (Pt1, Pn1), Behbahan (Pt2, Pn2), Bagh Mallek (Pt3, Pn3) and Shoushtar (Pt4, Pn4) were used to examine the specificity of the Pratylenchus primers. PCR reactions of $25 \mu \mathrm{l}$ contained the DNA template $(5 \mu \mathrm{l})$, $0.3 \mu \mathrm{l}$ units of Taq polymerase, $0.5 \mu \mathrm{l}$ dNTPs, $1 \mu \mathrm{l}$ each primer, $2.5 \mu \mathrm{l}$ 1X PCR buffer with $7.5 \mu \mathrm{l} \mathrm{MgCl}_{2}$. PCR amplification was performed in a thermocycler (Bio-Rad,) as follows: $95^{\circ} \mathrm{C}$ for $3 \mathrm{mins}$ followed by 35 cycles of $95^{\circ} \mathrm{C}$ for $30 \mathrm{~s}, 600 \mathrm{C}$ (PNEG/D3B5) or $62^{\circ} \mathrm{C}$ (PTHO/D3B) for $30 \mathrm{~s}$, and $72^{\circ} \mathrm{C}$ for $30 \mathrm{~s}$, with a final extension at $72^{\circ} \mathrm{C}$ for $7 \mathrm{~min}$ [15]. PCR products were separated in $1 \%$ standard agarose gels mixed with safe stain. Molecular size was estimated by a 100-bp DNA ladder (Fermentase). Besides, band pattern was photographed under UV light. In this study 140 nematodes were studied.

\section{Results}

All the qualitative characters including the number of lip, 
spermatheca (presence and shape), and the body length of the 2 species of Pratylenchus conformed to the original descriptions. Most of the quantitative characters of the populations also agreed with the original descriptions. However, a few characters fell outside the range of the original descriptions. For example, individuals of the both populations of $P$. thornai and P.neglectus had greater body lengths (425 to730 $\mu \mathrm{m}$ and 450 to $720 \mu \mathrm{m})$ than those reported in the original description. Morphometrics of the females $P$. thornei and $P$. neglectus are reported in Tables 1 and Table 2 .

All three DNA extraction methods which were used in this experiment were successful and the nematodes were tracked. Each species-specific primer was constructed to amplify DNA from the target species but to preclude the amplification of non-target Pratylenchus species

As a result, in comparison with Silva et al. [2] method for P. thornei and $P$. neglectus, modified methods of Madani et al. [1] and Waeyenberg et al. [3] were the best DNA extraction methods according to the band resolution which were created by gel electrophoresis and quantitative/ qualitative analysis of extracted DNA (Table 3). A common need in molecular diagnostics of lesion nematodes is to distinguish $P$. thornei from $P$. neglectus in field samples. Using PNEG and D3B5 speciesspecific primers produced a $144 \mathrm{bp}$ band for P. neglectus (Figure 1). However, these primers produced no band with extracted DNA from the species $P$. thornei. As it was expected, $\mathrm{PTHO} / \mathrm{D} 3 \mathrm{~B}$ species-specific primers produced a $288 \mathrm{bp}$ specific band with $P$. thornei (Figure 2) but no band was amplified with extracted DNA of P. neglectus (Figure 3). Each of the optimized primers amplified a unique PCR product from its respective target and did not produce an applicant from other Pratylenchus species. Furthermore, the presence and the size of the amplification product obtained from individual female nematodes were similar to those obtained from the D3 amplification products.
This assay showed that conserved D3 primers amplified DNA from all individuals of the three species, thus confirming the overall reliability of the PCR for a specimen tested.

\section{Discussion}

Morphological identification of Pratylenchus species relies on the observation of a specific stage of its life cycle. In addition, there is strong intra-specific variation along with few species-specific diagnostic characteristics [22,23]. The Morphometric differences have been reported to be the result of geographical distribution, ecophenotypic effects and different-hosts [24].

In this study the specimens conform closely to the earlier descriptions of $P$. thornei, but there exist some variations. Body length and breadth were measured 425-730 $\mu \mathrm{m}$ and 4.1-7.3; while Sher and Allen [25] and Pourjam et al. [26] reported them to be 450-770 $\mu \mathrm{m}, 5.5-8$ and 420-680 $\mu \mathrm{m}, 5.2-8$ respectively. Also compared with reports Yu [27] and Castillo \& Vovlas (2007) stylet length was samed $(16 \mu \mathrm{m})$ but $\mathrm{c}$ and body length were smaller and greater respectively. Also ć were measured $2.1 \mu \mathrm{m}$ that it was similar to Castillo \& Vovlas (2007) reports and V $(77.6 \mu \mathrm{m})$ was larger than Yu [27] reports with $76 \mu \mathrm{m}$. Specimens also conform closely to the earlier descriptions of $P$. neglectus but with some variations. The body length, the tail length and bw were measured 450-720 $\mu \mathrm{m}, 20-30 \mu \mathrm{m}$ and 22-14; while in Pourjam et al. [10] studies 340-590 $\mu \mathrm{m}, 13-33$ and 12-22 $\mu \mathrm{m}$ were reported respectively, and Filipjev and Schuurmans Stekhoven [28] reported the body length $0.31-0.5 \mathrm{~mm}$ and the tail length 20-18 have been reported. Also compared with reports Doucet and Cagnolo [29] Mizukubo and Minagawa [30] and Zedan and Geraert [31] body length and a were greater. Stylet length $(16.7 \mu \mathrm{m})$ in this study was greater than Mizukubo and Minagawa [30] with $16 \mu \mathrm{m}$ and Doucet and Cagnolo [29] with 16.6 $\mu \mathrm{m}$ reports also it was in the same range (16.5-17.5 $\mu \mathrm{m})$ of Zedan and

\begin{tabular}{|c|c|c|c|c|c|}
\hline \multirow[t]{2}{*}{ characters } & \multicolumn{4}{|c|}{ counties } & \multirow{2}{*}{$\begin{array}{c}\text { Total } \\
\text { Mean } \pm \text { SD }\end{array}$} \\
\hline & Masjed Solleiman & Behbahan & Bagh Mallek & Shoushtar & \\
\hline $\mathbf{n}$ & 5 & 5 & 5 & 5 & 20 \\
\hline $\mathbf{L}$ & $504-624(569.3 \pm 642.9)$ & $490-637(568 \pm 51.8)$ & $528-720(595 \pm 80.3)$ & $450-637(614 \pm 99)$ & $583.8 \pm 68.9(450-720)$ \\
\hline a & $30.3-51.4(38 \pm 8.4)$ & $25.2-32.8(28.9 \pm 3.3)$ & $24.5-33.5(29.2 \pm 3.5)$ & $21.6-31.5(26.7 \pm 3.7)$ & $30.7 \pm 6.5(21.6-51.4)$ \\
\hline b & $4.9-6.1(5.5 \pm 0.5)$ & $3.8-5.2(4.6 \pm 0.5)$ & $5.2-6.1(5.7 \pm 0.4)$ & $5-6.1(5.1 \pm 0.6)$ & $5.2 \pm 0.7(3.8-6.1)$ \\
\hline $\mathbf{b}^{\prime}$ & $3.9-11.9(6.2 \pm 3.3)$ & $3.9-4.8(4.3 \pm 0.3)$ & $3.2-6.4(5.1 \pm 1.3)$ & $3-10(8.7 \pm 3.4)$ & $6.1 \pm 2.8(3-11.9)$ \\
\hline c & $18.9-26.2(22.2 \pm 2.7)$ & $18.1-27.2(22.4 \pm 3.9)$ & $18.1-27.2(21.4 \pm 4.4)$ & $18.3-25(22.2 \pm 3.5)$ & $22.1 \pm 3.3(18.1-27.2)$ \\
\hline$c^{\prime}$ & $1.1-1.8(1.4 \pm 0.3)$ & $1.2-1.5(1.4 \pm 0.1)$ & $1.3-2.6(2.3 \pm 0.6)$ & $2.5(2.5 \pm 0)$ & $1.8 \pm 0.6(1.1-2.6)$ \\
\hline V & $81.7-81.9(81 \pm 0.9)$ & $81.2-83.6(82 \pm 1)$ & $81.3-83(82 \pm 0.8)$ & $82-83.6(82.6 \pm 0.4)$ & $82.5 \pm 0.9(81.2-83.6)$ \\
\hline Stylet & $13-20(16.8 \pm 3.1)$ & $15-18(16.6 \pm 1.3)$ & $15-18(16.4 \pm 1.5)$ & $19(17 \pm 2.3)$ & $16.7 \pm 2(13-20)$ \\
\hline m & $43.2-46(44.9 \pm 2.9)$ & $40.8-48.2(46.7 \pm 1.2)$ & $46-48.5(44.2 \pm 1.8)$ & $45.7-47(45 \pm 0.9)$ & $45.2 \pm 1.9(40.8-48.5)$ \\
\hline Oeso $^{1}$ & $90-122(111 \pm 13.6)$ & $95-120(108 \pm 11.5)$ & 75-110(99.6 \pm 15.3$)$ & $78-105(96.8 \pm 12.2)$ & $103.6 \pm 13.6(75-122)$ \\
\hline Over $^{2}$ & $25-30(28 \pm 2.7)$ & $20-45(30 \pm 9.3)$ & $20-40(31.8 \pm 9.9)$ & $22-43(39.4 \pm 3.9)$ & $32.3 \pm 8(20-45)$ \\
\hline Exc.pore & $70-79(75.4 \pm 4.5)$ & $71-89(81.6 \pm 8.4)$ & $67-75(72.8 \pm 8.7)$ & $69-82(77.4 \pm 5.1)$ & $76.6 \pm 7.1(67-89)$ \\
\hline Bw & $14-19(16.8 \pm 2.3)$ & $19-22(20 \pm 1.2)$ & $18-21(19.8 \pm 1.1)$ & $15-22(20.6 \pm 2.5)$ & $19.3 \pm 2.3(14-22)$ \\
\hline G\% & $10.6-21.7(15 \pm 4.1)$ & $13.8-16(13.5 \pm 2)$ & $11-14.5(14 \pm 2.5)$ & $12-14.5(13.2 \pm 3.4)$ & $15.41 \pm 3.9(10.6-21.7)$ \\
\hline Pus & $20-25(21.8 \pm 2.6)$ & $19-25(20.7 \pm 2.2)$ & $19-23(22.4 \pm 2.4)$ & $20(23 \pm 2.1)$ & $22.1 \pm 2.3(19-25)$ \\
\hline Tail & $22-30(25.4 \pm 4.2)$ & $25-30(27 \pm 2.7)$ & $20-27(24.4 \pm 3)$ & $23-27(25 \pm 1.6)$ & $25.5 \pm 2.9(20-30)$ \\
\hline ABW & $13-15(14 \pm 1)$ & $12-16(15.2 \pm 0.8)$ & $12-17(13.6 \pm 2.1)$ & $13-17(15 \pm 1.9)$ & $14.6 \pm 1.6(12-17)$ \\
\hline DGO & 2 & 2 & 2 & 2 & $2 \pm 0(2)$ \\
\hline $\mathrm{mB} \%$ & $42.3-66.7(53.3 \pm 9.9)$ & $51.3-63.9(59.2 \pm 5.6)$ & $54.5-62(51.3 \pm 4.3)$ & $44-63.9(52.8 \pm 8.9)$ & $54.2 \pm 7.5(42.3-66.7)$ \\
\hline GI & $60-95(86 \pm 14.7)$ & $65-85(78.2 \pm 13.8)$ & $60-90(85 \pm 11.2)$ & $90(90 \pm 0)$ & $84.8 \pm 11.4(60-95)$ \\
\hline V-an & $50-95(76 \pm 16.4)$ & $77-95(88.8 \pm 8.6)$ & $55-85(78.6 \pm 13.9)$ & $53-91(89.8 \pm 7)$ & $83.3 \pm 12.7(50-95)$ \\
\hline
\end{tabular}

1: Length of esophagus

2: The esophageal glands overlap the intestine

Table 2: Morphometric data of females of Pratylenchus neglectus from 4 counties were examined. Measurements are in $\mu \mathrm{m}$ and expressed as means \pm standard deviation (range). 


\begin{tabular}{|l|l|l|}
\hline $\begin{array}{l}\text { DNA extraction } \\
\text { method }\end{array}$ & Quantity $(\mathbf{n g} / \mu \mathrm{l})$ & Quality $\left(\mathbf{O D}_{\mathbf{2 6 0 / 2 8 0}}\right)$ \\
\hline Madani et al. [1] & $22.2-24.2$ & $0.57-0 / 76$ \\
\hline Waeyenberge et al. [3] & $310.6-346.9$ & $0.8-1.04$ \\
\hline Silva et al. [2] & $476-477.3$ & $1.5-1.67$ \\
\hline
\end{tabular}

Table 3: Quantity and quality of DNA extraction methods.

\section{Pn3 Pn2 Pn1 L}

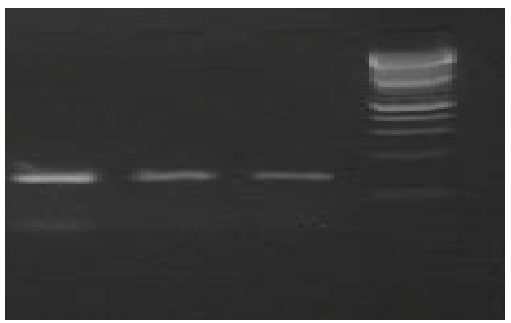

Figure 1: Specific polymerase chain reaction amplification for $P$. neglectus (144 bp) from pure cultures using species-specific primers PNEG/D3B5. DNA templates from the isolates Pn1, Pn2, Pn3; L: 100-bp DNA molecular weight ladder.

\section{L $\quad$ Nc $\quad$ Pn1 $\quad$ Pn2 $\quad$ Pn3 Pn4}

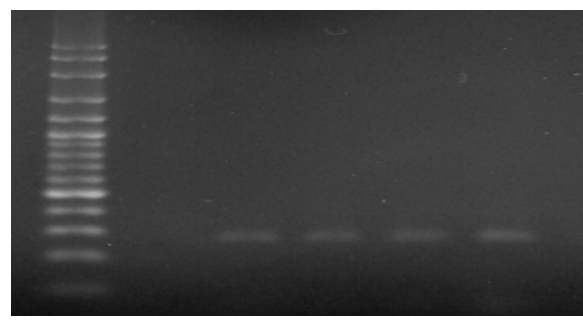

Figure 2: Specific polymerase chain reaction amplification for $P$. thornei (288 bp) from pure cultures using species-specific primers PTHO/D3B. DNA templates from the isolates $\mathrm{Pn} 1, \mathrm{Pn} 2, \mathrm{Pn} 3, \mathrm{Pn} 4 ; \mathrm{Nc}$ : negative control without DNA template; L: 100-bp DNA molecular weight ladder.

\section{Nc Pt1 Pt2 Pt3 Pt4 Pn1 Pn2 Pn3 Pn4 Nc L}

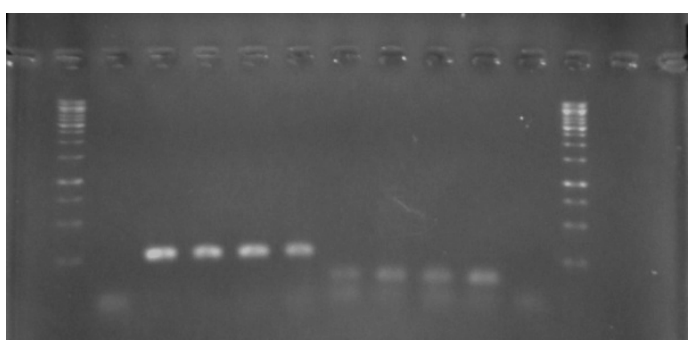

Figure 3: Specific polymerase chain reaction amplification for $P$. thornei (288 $\mathrm{bp})$ and $P$. neglectus (144bp) from pure cultures using species-specific primers PTHO/PENG. DNA templates from the isolates Pt1, Pt2, Pt3, Pt4, Pn1, $\mathrm{Pn} 2, \mathrm{Pn} 3, \mathrm{Pn} 4$; Nc: negative control without DNA template; L: 1000-bp DNA molecular weight ladder.

Geraert [31] reports. In this study b were measured $5.2 \mu \mathrm{m}$ that was greater than Zedan and Geraert [31] reports with 3.6-3.8 $\mu \mathrm{m}$ but was smaller than Mizukubo and Minagawa [30] with $5.4 \mu \mathrm{m}$ and Doucet and Cagnolo [29] with $5.8 \mu \mathrm{m}$ reports. These variations could be related to the high variability, diversity and wide distribution of Pratylenchus spp. Under different climatic conditions, certain morphological characters, such as the number of lip annuls, the shape of the spermatheca, and the structure of the lateral field, are generally reliable for the identification of Pratylenchus species [22]. However, the recognition of these characters requires substantial and specialized training and, even then, multiple adult female specimens are necessary for reliable species diagnosis. The qualitative morphological characteristics of the Pratylenchus populations used in this study followed the original species descriptions, but some morphometric discrepancies were found. Such morphometric variations in Pratylenchus species have been previously reported [32]. Townshend [33] reported that morphometric variations existed among populations of $P$. penetrans associated with strawberry and those associated with celery in Ontario, Canada. Furthermore, variations in size were also found among populations recovered from the same host (strawberry) but collected from different geographical areas Townshend [33]. Similarly, Doucet et al. [34] reported that temperature significantly influences the morphometrics of individuals derived from a single isolate of $P$. vulnus. All these findings indicate that morphometric characters are not always reliable as primary characters for the Pratylenchus species identification.

One of the best choices for diagnostic purposes, i.e. the specific identification of several nematode species, is the application of molecular genetics techniques, especially those which are PCR-based [35].

Manual methods for nematodes DNA extraction were used in the present study. Madani et al. [1] and Waeyenberg et al. [3] along with some modification were the best DNA extraction methods for $P$. thornei and $P$. neglectus. Therefore, these methods are recommended for the both mentioned species, but the other species of genus Pratylenchus should be reviewed for DNA extraction methods. Latter methods had the highest sensitivity and validity for identifying and tracking nematodes. These manual methods are recommended due to their low cost in comparison with expensive commercial kits. In addition, the quality and quantity of the samples were also competitive with commercial kits.

In this study, two pairs of species-specific primers were used for the PCR amplification. PTHO/D3B specific primers described by Al-Banna et al. [14] were used for P. thornei and produced a $288 \mathrm{bp}$ band. However, no band was amplified with the extracted DNA of $P$. neglectus. PNEG/D3B5 primers also produced a 144 bp band with $P$. neglectus while no band was amplified with the extracted DNA of $P$. thornei. These results are consistent with results of Yan et al. [15] study. These species were separate due the differences in the size of the pieces after electrophoresis of PCR. Moreover, the forward primers (PTHO, PNEG) used in the study are designed from domain variable parts D3 in large subunit nuclear ribosomal RNA, because this variable portion can make the identification of different species possible. Backward primers are designed into a fixed part of the domain D3. Because the use of two different conserved areas in the domain D3, we can use the factor 'fragment length difference' as a factor in identifying various species. D3 expansion region for Pratylenchus is specific to the level of the species and does not vary among populations of conspecifics [36].

These species-specific primers should be applicable to diagnostics of both pure and mixed Pratylenchus populations, since single females can be tested. However, until the PCR identification has been validated on a wide collection of field isolates, parallel identification with qualitative morphological techniques is recommended for key samples [14].

\section{Acknowledgments}

This research was supported by the Department of Plant Protection and 
Citation: Fayazi F, Farokhi-Nejd R, Ahmadi AR, Memari HR, Bahmani Z (2012) Molecular and Morphometric Identification of $P$. Thornei and $P$. Neglectus in Southwest of Iran. J Plant Pathol Microb 3:123. doi:10.4172/2157-7471.1000123

the Department of Agronomy and Plant Breeding, College of Agriculture, Shahid Chamran University, Ahvaz, Iran. We thank Yan, G., Smiley, W. R. and Safara, S. for their help.

\section{References}

1. Madani M, Subbotin SA, Moens M (2005) Quantitative detection of the potato cyst nematode, Globodera pallida, and the beet cyst nematode, Heterodera schachtii, using Real-Time PCR with SYBR green I dye. Mol Cell Probes 19: 81-86.

2. Silva AT, Penna JCV, Goular LR, Dos Santos MA, Arantes NE (2000) Genetic variability among and within races of Heterodera glycines Ichinoche assessed by RAPD markers. Genetics and Molecular Biology 23: 323-329.

3. Waeyenberge L, Ryss A, Moens M, Pinochet J, Vrain TC (2000) Molecular characterization of 18 Pratylenchus species using rDNA restriction fragment length polymorphism. Nematology 2: 135-142.

4. Anonynomous (2009b) Faostat 2009.

5. Anonynomous (2009a) Agriculture statistic. Crops 1: 137.

6. Lownsberry B F (1956) Pratylenchus vulnus, primary cause of the root lesion disease of walnuts. Phytopathology 4: 376-379.

7. McKenry MV (1989) Damage and development of several nematode species in a plum orchard. Appl Agricultural Research 4: 10-14.

8. Castillo P, Gomez-Barcina A, Jime'nez-Dı'az RM (1996) Plant parasitic nematodes associated with chickpea in Southern Spain and on reproduction of Pratylenchus thornei. Nematologica 42: 211-219.

9. Di Vito M, Greco N, Halila HM, Mabsoute L, Labdi M, et al. (1994) Nematodes of cool-season food legumes in North Africa. Nematologia Mediterranea 22: 3-10.

10. Pourjam E, Kheiri A, Geraert E, Alizadeh A (1999) Variations in Iranian population of Pratylenchus neglectus and $P$. thornei (Nematoda: Pratylenchidae). Iran J Plant Pathol 35: 23-27.

11. Ahmadi AR, Tanha-Maafi Z, Fayazi F (2010) Identification and population density of cyst nematodes and root-lesion nematodes in Khuzestan province. $19^{\text {th }}$ Iranian Plant Protection Congress, Tehran 548.

12. Handoo ZA, Golden AM (1989) A key and diagnostic compendium to the species of the genus pratylenchus filipjev, 1936 (lesion nematodes). J Nematol 21: $202-218$.

13. Loof PA (1991) The family Pratylenchidae Thorne 1949. Manual of agricultural nematology 363-421.

14. Al-Banna L, Ploeg AT, Williamson VM, Kaloshian I (2004) Discrimination of six pratylenchus species using PCR and species-specific primers. J Nematol 36 : $142-146$

15. Yan G, Smiley RW, Okubara PA, Easley SA, Sheedy JG, et al. (2008) Detection and discrimination of Pratylenchus neglectus and $P$. thornei in DNA extracts from soil. Plant Disease 92: 1480-1487.

16. Jenkins W R (1964) A rapid centrifugation flotation technique for separating nematodes from soil. Plant Disease Reports 48: 692.

17. O' Bannon J H, Taylor A L (1968) Migratory endoparasitic nematodes reared on carrot discs. Phytopathology 58: 385.

18. Moody EH, Lownsbery BF, Ahmed JM (1973) Culture of the Root-Lesion Nematode Pratylenchus vulnus on Carrot Disks. J Nematol 5: 225-226.

19. Whitehead AG, Hemming JR (1965) A Comparison of some quantitative methods of extracting small vermiform nematodes from soil. Annals of Applied Biology 55: 25-38.

20. Young TW (1954) A cautiously optimistic vision for marker-assisted breeding Plant Disease Reports 38.

21. De Grisse D (1969) Redescription and modification of some techniques used in the study of nematodes phytoparasitaires. MEDED, Empire Ghent Faculty of Agricultural Sciences 34: 351-369.

22. Loof PAA (1978) The genus Pratylenchus filipjev, 1936 (Nematoda: Pratylenchidae): A review of its anatomy, morphology, distribution, systematics, and identification. Research Information Center.

23. Orui Y (1996) Discrimination of the main Pratylenchus species (Nematoda: Pratylenchiidae) in Japan by PCR-RFLP analysis. Appl Entomol Zool 31: 505-514.
24. Goodey J B (1952) The influence of theh osto nt he dimensions of the plant parasitic-nematode Ditylenchus destructor. Ann appl Biol 39: 468-474.

25. Sher S A (1953) Revision of the genus Pratylenchus (Nematoda: Tylenchidae). (University of California Publications in Zoology) 57: 441-447.

26. Pourjam E, kheiri A, Geraert E, Alizadeh A (1997) The study of morphology and classification of Pratylenchus species in north of Iran. Plant Disease 76 868-874.

27. YU Q (1997) First report of Pratylenchus thornei from spring wheat in southern Ontario. Can J Plant Pathol 19: 289-292.

28. Filipjev I N, Schuurmans Stekhoven JH (1941) A manual of agricultural helminthology. European Journal of Plant Pathology 47: 234-236.

29. Doucet M E, Cagnolo S (1998) Variabilidad intra e inter-especefica de caracteres morfométricos en poblaciones del orden Tylenchida (Nematoda) provenientes de Argentina. Nematologia Mediterranea 26: 231-236.

30. Mizukubo T, Minagawa N (1991) Morphometric differentiation of Pratylenchus neglectus (Rensch, 1924) and P. gotohi n. sp. (Nematoda: Pratylenchidae) Japanese Journal of Nematology 21: 26-42.

31. Zeidan A B, Geraert E (1991) Pratylenchus from Sudan, with the description of two new species (Nemata: Tylenchida). Revue de Nématologie 14: 261-275.

32. Doucet M E, Lax P, Pinochet J (1998) Variability of some external characters in Pratylenchus vulnus Allen \& Jensen, 1951 (Nematoda; Tylenchida). App Nematol 21: 205-206.

33. Townshend JL (1991) Morphological Observations of Pratylenchus penetrans from Celery and Strawberry in Southern Ontario. J Nematol 23: 205-209.

34. Doucet M, Paola L, Julio ADR, Jorge P, Pierre B (2001) Temperature-induced morphometrical variability in an isolate of Pratylenchus vulnus Allen \& Jensen, 1951 (Nematoda; Tylenchida). Nematology 3: 1-8.

35. Da Conceic ão ILPM, Dos Santos MCV, Abrantes IMdeO, Santos MNS (2003) Using RAPD markers to analyse genetic diversity in Portuguese potato cyst nematode populations. Nematology 5: 137-143.

36. Al-Banna L, Williamson V, Gardner SL (1997) Phylogenetic analysis of nematodes of the genus Pratylenchus using nuclear 26S rDNA. Mol Phylogenet Evol 7: 94-102. 